\title{
APPLICATION OF BIOREMEDIATION TECHNIQUES AS A POTENT INPUT FOR THE DECONTAMINATION OF BITUMEN-POLLUTED WATER
}

\author{
Eganoosi Esme ATOJUNERE ${ }^{1 *}$, Kolawole OGEDENGBE ${ }^{2}$
}

\section{Abstract}

Large deposits of natural bitumen are found in some areas of Ondo State, Nigeria. Although the mineral is still unexploited, its seepage is enough to negatively influence the environment, especially water resources. This work was designed to determine the potential of four Bitumen Utilizing Microbes (BUM) for the purification of Bitumen-Polluted Water (BPW). BUM were screened differently with a control on the BPW drawn from the affected communities. The bitumen's degradation was determined using a supplemented enrichment medium with a sample of the BPW, and the growth was monitored by taking temperature readings, $\mathrm{pH}$ values, the optical density at $600 \mathrm{~nm}$, and the total viable count (TVC) on days 7, 14, 21 and 28 respectively. The bitumen removal rate varied with the time of the incubation until after the third week, when the lack of nutrients supposedly set in and toxic metabolites started building up, which slowed down the process. The BUMs were identified as Bacillus firmus, Bacillus lentus, Pseudomonas aeruginosa, and Bacillus alvei. The bitumen removal trend showed that Pseudomonas aeruginosa $>$ Bacillus firmus $>\mathrm{Ba}$ cillus lentus $>$ Bacillus alvei and the control the least amount of removal.

\section{Address}

1 Dept. of Systems Engineering, University of Lagos, Lagos, Nigeria

2 Dept. of Agricultural and Environmental Engineering, University of Ibadan, Ibadan, Nigeria

* Corresponding author: eatojunere@unilag.edu.ng

\section{Key words}

- Bioremediation,

- Water,

- Pollutants,

- Pseudomonas aeruginosa,

- Removal Efficiency (RE).

\section{INTRODUCTION}

The use of biological methods for the clean-up of hydrocarbon-polluted water has been receiving global attention (Atlas and Bartha,1992). Their acceptance is not unconnected with their effectiveness during the removal of crude oil in the Gulf of Alaska from the Exxon Valdez oil spill in 1989. Also, the pollution of water bodies by bitumen has been reported in other areas, including Canada, Venezue- la, Trinidad and Tobago, and Nigeria. Bitumen is a complex mixture of hydrocarbons that have similar physico-chemical characteristics to crude oil such as density with just some slight differences. It includes a high degree of viscosity and a hydrocarbon content, which prevents it from flowing under natural conditions (Adegoke, 2000). An increase in temperature may cause bitumen to flow and transport oily material to water bodies, rivers, and dugout wells after rainfall events. This is the experience of 
some communities in the bitumen-rich areas of the Ondo State, Nigeria. Bitumen is less dense than water, which explains why bitumen mats have been seen floating on the affected water bodies, thereby resulting in their accumulations on riverbanks. Bitumen can be partially removed by scrapping it off from the surface of water, but still leaving the dissolved portions in the polluted water. Obviously, there is an urgent need for decontamination. Bitumen-polluted water has been found to contain suspended oily materials, toxic metals, and dissolved petroleum hydrocarbons at different concentrations (Atojunere et al., 2018; Atojunere and Ogedengbe, 2019). Inhabitants of bitumen-rich communities in Nigeria are peasant farmers that cultivate food and cash crops, so that irrigating fields with bitumen-polluted water is not a good practice. Low agricultural outputs of such crops have since been reported (Atojunere et $a l ., 2010)$. The ideal bioremediation choices for decontamination include a low cost, effectiveness, and sustainability. Microorganisms can play an important role in the removal of pollutants emanating from mineral resources found in the environment. The use of Bitumen Utilizing Microbes (BUM) after their isolation from a local carbon source and introduced as an inoculum to decontaminate polluted water is one of the ways to determine the efficiency of their pollutant removal. Bioremediation is the biological conversion of organic contaminants to harmless chemical by-products (water and carbondioxide) that are lower in free energy (Chaineau et al., 2005). They produce biological catalysts that lower the activation energy of the polluted media before attacking the pollutants known as biosurfactants. The biosurfactant produced reduces the surface tension at the interface of the microbes and polluted media during decontamination, thereby increasing pollutant removal (ASCE, 2004). Hydrocarbon-degrading microorganisms have specific catabolic genes in the form of plasmids, which help in degrading pollutants. Among the most studied biosurfactants produced by a microorganism that have the potential to decontaminate hydrocarbon-polluted water include rhamnolipid (glycolipid), which is secreted by Pseudomonas aeruginosa (Atlas, 1981; Obayori, 2008). Microorganisms with this potential belong among the bacteria and fungi genera Pseudomonas spp, Bacillus spp and Acinetobacter, respectively (Amund and Igiri, 2000; Nwachukwu, 2001; Oyeti- bo et al., 2010). The rate of biodegradation has been reported to be influenced by some environmental conditions (Rittman and McCarty, 2001; Umanu et al., 2013), i.e., the availability of substrates, nutrients, and the temperature, especially mesophilic temperatures from 20 to $30^{\circ} \mathrm{C}$, which have been found to be best for bioremediation. Other conditions are the $\mathrm{pH}$ and moisture content. For example, the temperature influences the biodegradation of hydrocarbons by causing changes in (1) the physical nature and chemical composition of the hydrocarbons; (2) the rate of the hydrocarbon's metabolism by microorganisms; and (3) the composition of the microbial community (Alexander, 1999). This work was designed to determine the ability of some Bitumen-Utilizing Microorganisms (BUM) to detoxify bitumen-polluted water.

\section{MATERIALS AND METHODS}

\subsection{The Sampling Areas}

The water samplings were taken along polluted streams in the local government areas of the Ondo State, Nigeria. In these areas, there are large deposits of untapped natural bitumen deposits both above and below the soil surface. Bitumen seepages are plentiful enough to pollute major fresh water bodies and their tributaries in neighboring settlements, i.e., Agbabu, Ilubirin, Boridele, and Lodasa. Major rivers in the area are the Oluwa, Oni, Italita and Siluko. These waterbodies are sources of water for the inhabitants. The bitumen deposits in this area are found at the $6^{\circ} \mathrm{N}, 5^{\circ} \mathrm{E}$ coordinates. The main occupations of the people in the area are farming (including fish farming) and log and latex production. The sample water taken from some of the communities' streams and wells were pooled together as bitumen-polluted water and was transported to a laboratory in Lagos, Nigeria, for a bioremediation experiment.

\subsubsection{Culturing of Bitumen Utilizing Microorganisms (BUMs)}

The isolation of the BUMs were in line with the procedures in Leahy and Colwell (1990). The Raymond nutrient agar used for this work contained $0.5 \mathrm{~g} / \mathrm{L}\left(\mathrm{K}_{2} \mathrm{HPO}_{4}\right), 0.2 \mathrm{~g} / \mathrm{L}\left(\mathrm{MgSO}_{4} 7 \mathrm{H}_{2} \mathrm{O}\right), 0.02 \mathrm{~g} / \mathrm{L}$ $\left(\mathrm{CaCl}_{2}, 2 \mathrm{H}_{2} \mathrm{O}\right), 3$ drops of $60 \%$ Iron II chloride 
$\left(\mathrm{FeCl}_{3}\right) ; 0.2 \mathrm{~g} / \mathrm{L}$ of $\left(\mathrm{NH}_{4}\right)_{2} \mathrm{SO}_{4}$, and $2.0 \mathrm{~g} / \mathrm{L}$ of sodium chloride $(\mathrm{NaCl})$. A copper wire loop was heated until it was red-hot and then allowed to cool. It was used to scoop $0.1 \%$ aliquot from the sampled $\mathrm{Bi}$ tumen-Polluted Water (BPW). The prepared Minimum Salt Medium (MSM) was poured into a Petri dish and was allowed to set. A drop of the BPW was uniformly spread on the entire surface of the Petri dish with a glass spreader during the cultivation. The Petri dish with the MSM and BPW was placed inside a Gallenkamp incubator set at a temperature of up to $38^{\circ} \mathrm{C}$ for the growth to occur. After the cultivation, the production of pure BUM isolates went through several sub-cultivation processes. Four pure microbial cultures were produced through several sub-cultivation processes. A copper wire loop was heated until it was red-hot and then allowed to cool. It was used to scoop distinctive colonies of microorganisms that had grown on the surface of the Petri dish placed inside the incubator. This process was repeated until the pure BUM isolates were produced.

\subsubsection{Screening the potential of the BUMs for bitumen removal}

The experiment involved five clean $250 \mathrm{ml}$ Erlenmeyer flasks, which were labelled 1 to 4 and ' $C$ ' for the control. They were filled to a $100 \mathrm{ml}$ level with raw bitumen-polluted water for the treatment. Fifty $\mathrm{ml}$ of the MSM were added to each flask before dispensing the aliquot Bacillus firmus, Bacillus lentus, Pseudomonas aeruginosa, and Bacillus alvei to flasks 1, 2, 3, and 4 respectively; no inoculum was added to flask $\mathrm{C}$ as shown in Figures $1 \mathrm{~A}-\mathrm{B}$ and $2 \mathrm{~A}$ B. A wire loop was heated to red hot and allowed to cool. It was used to transfer each of BUM isolates from the pure culture that was stored in slant bottles. The optical density of the inocula was adjusted before it was seeded into each flask. At 1-week intervals the bitumen's Removal Efficiency (RE) was determined through tests using a standard method (APHA, 2005). Water samples from each flask were taken for physico-chemical analyses. Some of the variables monitored included the temperature, time, $\mathrm{pH}$ value, turbidity, microbial population counts, and Total Petroleum Hydrocarbon (TPH). The enumeration of the colonies of BUMs was carried out using the Heterotrophic Counting Method. The tools and materials, test tubes, an isolate dispenser, a spirit lamp, and culture plates that were employed during the experiments were aseptically handled to avoid contamination. The laboratory workbench was disinfected using ethanol. The experiment was done in duplicate, and the flask tips were plugged with cotton, wrapped in aluminum foil, and placed inside the incubator for 30 days. Descriptive statistics were used to obtain the differences in the environmental variables monitored.

\subsubsection{The Gram Staining and Biochemical Tests}

During the Gram staining, a wire loop was heated until it was red hot and then allowed to cool. It was used to scoop colonies of the BUM, which was thoroughly spread to cover the approximate area of each slide of $1 \mathrm{~cm}$ by $3 \mathrm{~cm}$ using a glass spreader. The thin smears were air-dried for two seconds. They were fixed on a slide by passing each slide horizontally three times over the lit spirit lamp. Each identified BUM for the test was produced on a slide in duplicate. Overheating the slides was avoided by regularly testing the temperature of the slides by touching them manually with the hand. The slides were soaked with four stains, one at a time. The basic stain (crystal violet) solution was used for up to one minute and was washed off with tap water. These steps were repeated for the three remaining solution stains, namely Gram's iodine solution (mordant) for only 1 minute, 95\% alcohol, and safranin solutions. Photomicrographs of the BUMs at a magnification of $x 1000$ of the BUMs were taken after the examination of the slides using a grey-enameled binocular microscope made by Zeiss (Germany) as shown in Figures 3A-B and 4A-B. Biochemical tests on the BUMs were carried out at the Nigerian Institute of Medical Research, Lagos, Nigeria, in line with standard procedures (Holt et al.,1994). The BUM isolates were tested for sugar fermentation, the indole test, calatase, motility, etc.

\section{RESULTS AND DISCUSSION}

A preliminary study indicated that some water bodies in the bitumen-affected area contain suspended oily materials, toxic metals, and dissolved petroleum hydrocarbons at different concentrations. 


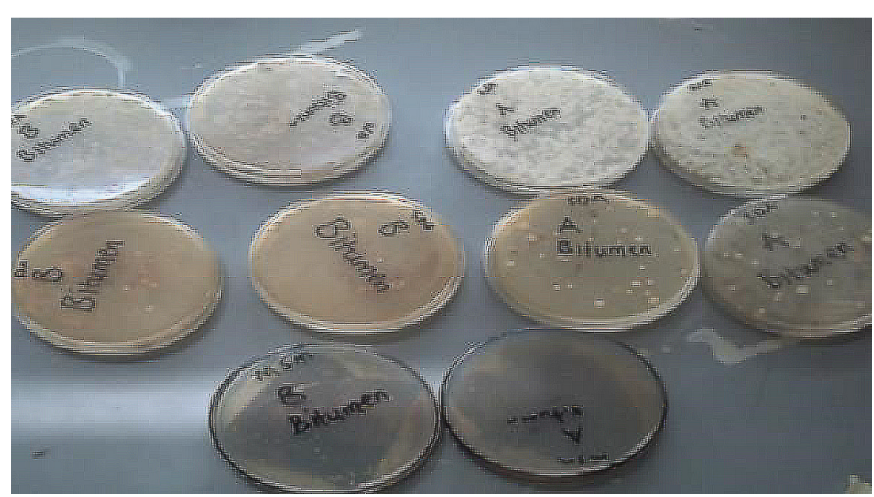

Fig. 1 A) Isolation and cultivation processes;

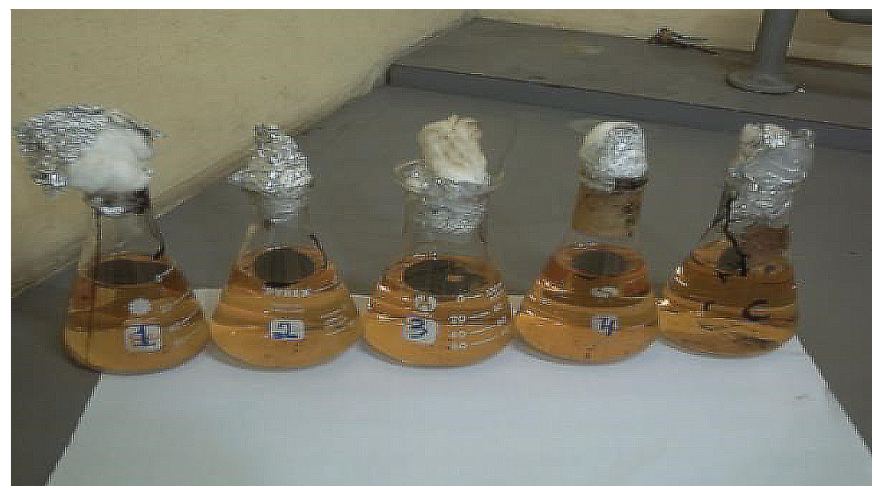

Fig. 2 A) Bioremediation after 0-5 minutes with low turbidity;

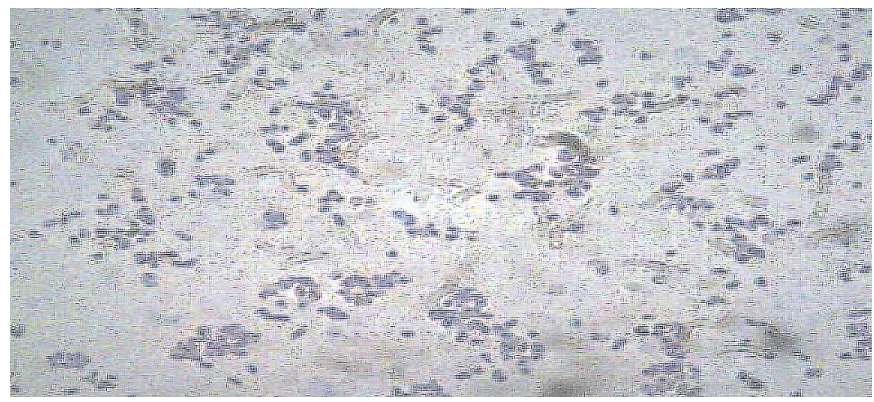

Fig.3 A) Photomicrograph of the Bacillus alvei;

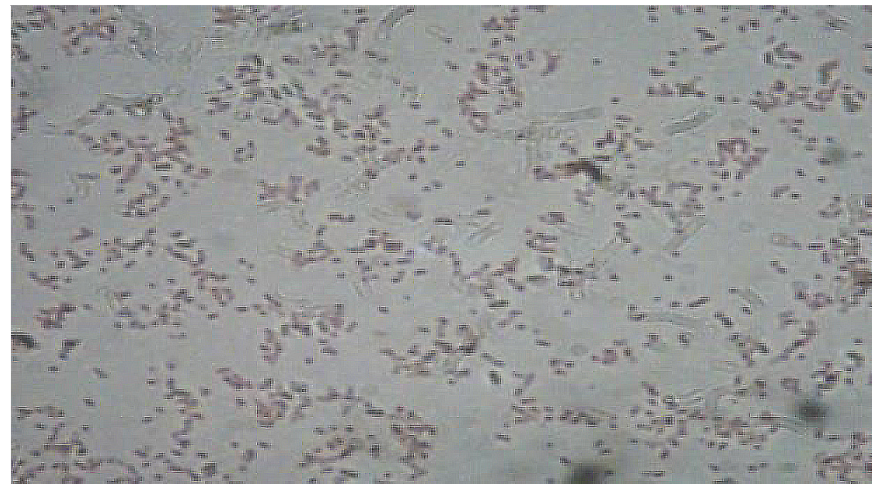

Fig. 4 A) Photomicrograph of the P. aeruginosa;

These contaminants were due to the presence of bitumen in the affected region. The four distinct $\mathrm{Bi}$ tumen Utilizing Microorganisms (BUMs) isolated were identified as Bacillus firmus, Bacillus lentus,

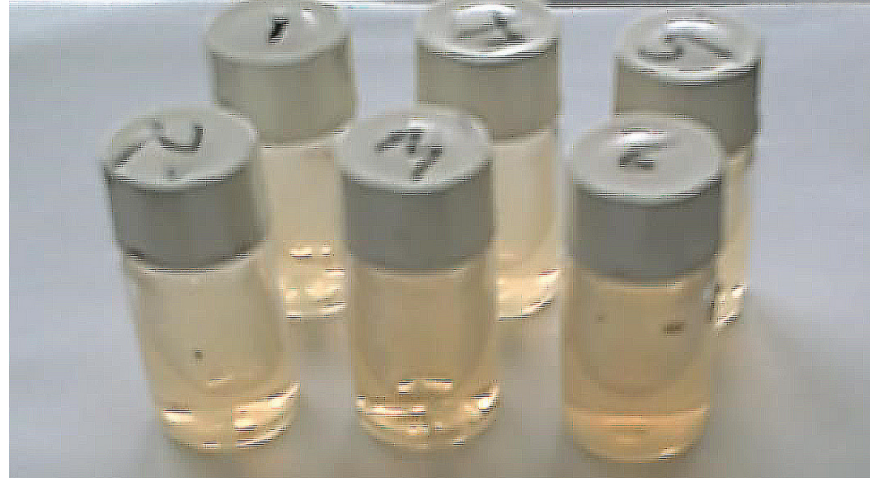

B) Pure cultures of the isolates

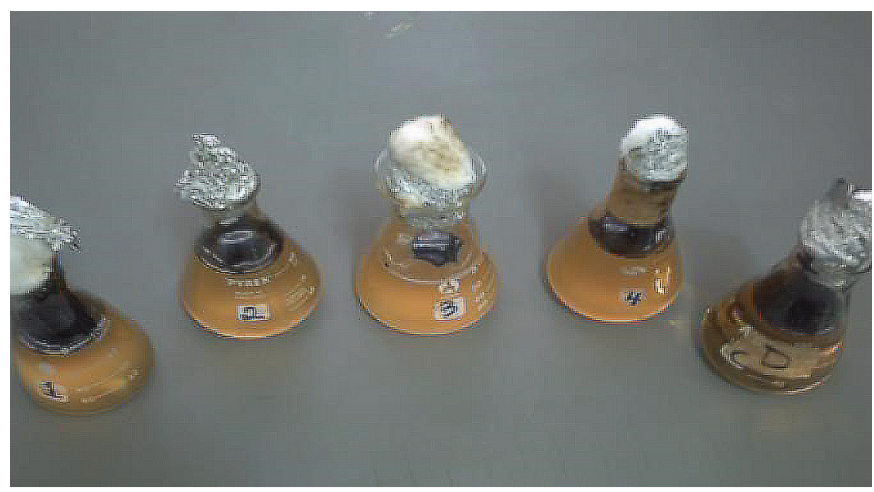

B) Bioremediation after 24 hours with high turbidity

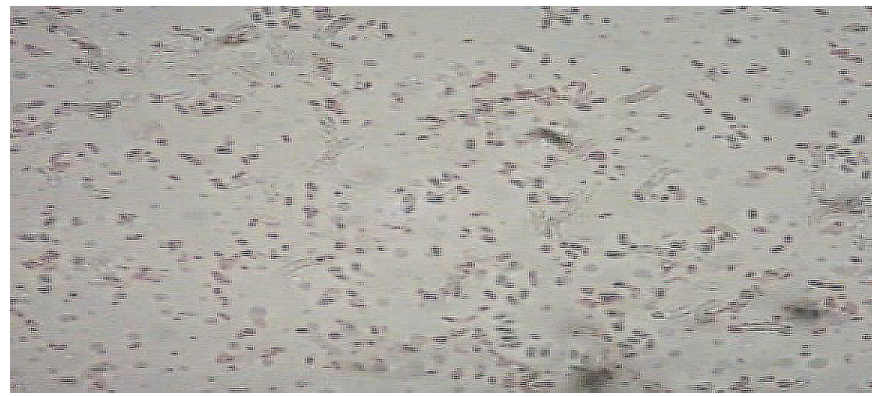

B) Photomicrograph of the Bacillus firmus

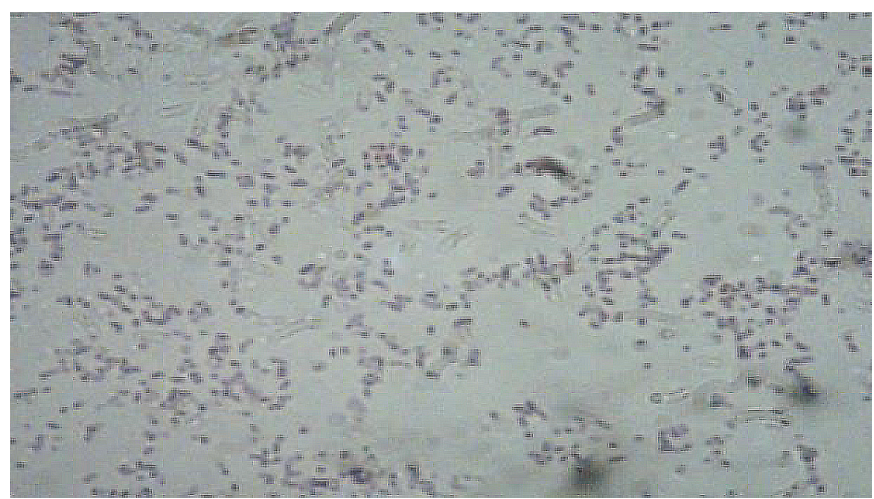

B) Photomicrograph of the Bacillus lentus

Pseudomonas aeruginosa, and Bacillus alvei. They are native microorganisms and thrived well when introduced as pure inocula to treat the Bitumen-Polluted Water in all the experimental flasks except for 
the control. They are indigenous microbes and expected to adapt to the mixture more quickly than foreign microbes. It was determined that a temperature between 30 to $40^{\circ} \mathrm{C}$ was most suitable for bitumen removal by the BUMs because they are found to be mesophilic. Tables 1 to 4 show the average values of the test indicators, the $\mathrm{pH}$ as well as the turbidity, and the bitumen removal rate of the Bitumen-Polluted Water. They were facultative microorganisms that showed variations in their abilities during the biochemical tests such as the fermentation, indole and motility tests; the results are depicted in Table 5 . The colony counts of the bitumen-utilizing microorganisms increased over time with an optimum $\mathrm{pH}$ between 7 to 9 . The removal rates were as shown in Figures 5 to 6 respectively. The test results confirmed that the Pseudomonas aeruginosa in experiment flask 3 had the best bitumen removal rate of $1.210^{5}$ to $2.510^{12}$ for the microbial population with an optimum $\mathrm{pH}$ of about 8.0 and a turbidity value of 2500 NTU. These findings agree with some earlier works that the microorganism plays a crucial role in detoxifying a contaminated environment. They suggest that some microorganisms have multiple pathways for attacking a substrate for complete removal as demonstrated on bitumen. Several authors, for example, Amund and Igiri (2000), Nwachukwu (2001), Chaineau et al. (2005), Oboh, et al. (2006), Obayori (2008), Oyetibo et al. (2010), and Umanu et al. (2013), have reported these versatile characteristics of Pseudomonas aeruginosa in pollutant removal, due to its different metabolic pathways. Furthermore, Pseudomonas aeruginosa showed the highest ability to degrade bitumen under the stringent environmental conditions of the temperature, $\mathrm{pH}$ and time, when compared with the other BUMs in Flasks 1, 2 and 4, respectively. There was a decline in the third week when the lack of nutrients supposedly occurred, followed by the production of toxic metabolites and the decay of dead microorganisms. This might have made the mixture toxic to the BUM, which reduced their rate of biodegradation. The removal followed this trend: Pseudomonas aeruginosa $>$ Bacillus firmus $>$ Bacillus lentus $>$ Bacillus alvei $>$ control. The lowest value was from the control flask; this finding was not surprising, as no inoculum was added to it during the experiment. The trend of bitumen removal had the Pseudomonas aeruginosa performing better than the Bacillus alvei and the Bacillus firmus preforming better than the Bacillus lentus, which was better than the control as shown in Fig. 7. The Pseudomonas aeruginosa performed better than the Bacillus alvei, while the Bacillus firmus performed better than the Bacillus lentus, and the lowest removal was better than the control. This also supports the ability of Pseudomonas aeruginosa to gobble up bitumen as a source of carbon that transforms the pollutants to a non-harmful form. It can grow well on a contaminant before treatments, so the concept of reintroducing it as a pure culture for decontamination increases the decontamination rate. The bitumen removal trend obeyed the growth curve of the increase from the first phase to the exponential phase and became stagnant at the stationary phase. The reduction might suggest that at the death stages, where the isolates started to die off, was due to a shortage of nutrients and the building up of toxic metabolites. The increase in turbidity suggests that the BUM were able to utilize the bitumen and its associated contaminants, which make them multiply. The ptimum $\mathrm{pH}$, for the bioremediation was in the alkaline range. The effects of the temperature, $\mathrm{pH}$ and time were significantly different during the screening process. The percentage of the bitumen removal ranged from 33.81 to $41.24 \%$ at the highest, followed by 21.70 to $24.41 \%$; the control flask showed the lowest rate of removal. These findings agree with some previous works, e.g., Okoh (2006), Adebusoye et al. (2007), and Olabemiwo et al. (2011), although their treated effluents were not Bitumen-Polluted Water. The variations in the level of bitumen removed by each inoculum might suggest that single microorganisms cannot completely remove all the pollutants present in contaminated media; however, using a mixed culture of microorganisms might also have negative effects such as competition for food and nutrients among the microorganisms, which might reduce the pollutant removal rate. The bioremediation was cheaper and effectively removed the pollutants as in Fig. 7. Pseudomonas aeruginosa showed the best bitumen removal rate. Seeding and boosting some environmental factors would increase its efficiency. The screening indicated ways of optimizing the process by identifying those microorganisms that were actually involved in the removal process rather than using an array of microorganisms together. The small-to-medium scale approach was effective 
Tab. 1 Total Viable Count (TVC) CFU/ml of BUM weeks 1 to 5

\begin{tabular}{llllll}
\hline Microbial population for Inoculum & 1 day & 7 days & 14 days & 21 days & 30 days \\
\hline Bacillus firmus & $5.0 \times 10^{4}$ & $1.4 \times 10^{6}$ & $1.7 \times 10^{7}$ & $4.0 \times 10^{9}$ & $3.8 \times 10^{11}$ \\
Bacillus lentus & $1.0 \times 10^{5}$ & $2.7 \times 10^{6}$ & $6.0 \times 10^{7}$ & $1.8 \times 10^{9}$ & $1.6 \times 10^{11}$ \\
P.aeruginosa & $9.0 \times 10^{5}$ & $8.0 \times 10^{6}$ & $6.5 \times 10^{8}$ & $7.4 \times 10^{11}$ & $5.2 \times 10^{12}$ \\
Bacillus alvei & $2.4 \times 10^{5}$ & $4.8 \times 10^{6}$ & $2.4 \times 10^{8}$ & $2.3 \times 10^{9}$ & $2.5 \times 10^{9}$ \\
C & $4.0 \times 10^{5}$ & $3.2 \times 10^{6}$ & $5.0 \times 10^{7}$ & $5.1 \times 10^{9}$ & $5.4 \times 10^{9}$ \\
\hline
\end{tabular}

Tab. $2 \%$ Total Petroleum Hydrocarbon (TPH) mg/L of BUM at weeks 1 to 5

\begin{tabular}{lccccc}
\hline TPH values & $1^{\text {st }}$ week & $2^{\text {nd }}$ week & $3^{\text {rd }}$ week & $4^{\text {th }}$ week & $5^{\text {th }}$ week \\
\hline P. aeruginosa & 33.81 & 39.00 & 41.10 & 41.22 & 34.00 \\
Bacillus alvei & 22.29 & 24.20 & 24.38 & 24.39 & 22.00 \\
Bacillus firmus & 21.70 & 23.31 & 24.40 & 24.41 & 22.60 \\
Bacillus lentus & 18.60 & 20.92 & 22.55 & 22.61 & 17.50 \\
C & 1.23 & 1.34 & 1.38 & 1.37 & 1.20 \\
\hline
\end{tabular}

Tab. 3 pH values of BUM during weeks 1 to 5

\begin{tabular}{|c|c|c|c|c|c|}
\hline $\mathrm{pH}$ for Inocula & $1^{\text {st }}$ week & $2^{\text {nd }}$ week & $3^{\text {rd }}$ week & $4^{\text {th }}$ week & $5^{\text {th }}$ week \\
\hline Bacillus firmus & 8.90 & 8.80 & 8.30 & 8.70 & 8.60 \\
\hline Bacillus lentus & 8.90 & 8.40 & 8.70 & 8.50 & 8.70 \\
\hline Pseudomonas aeruginosa & 8.70 & 8.40 & 8.60 & 8.60 & 8.80 \\
\hline Bacillus alvei & 8.90 & 8.60 & 8.90 & 8.40 & 8.90 \\
\hline $\mathrm{C}$ & 8.80 & 8.70 & 8.50 & 8.60 & 8.50 \\
\hline
\end{tabular}

Tab. 4 Turbidity (Nephelometric Turbidity Unit - NTU) values at weeks 1 to 5

\begin{tabular}{|c|c|c|c|c|c|}
\hline Inoculum & $1^{\text {st }}$ week & $2^{\text {nd }}$ week & $3^{\text {rd }}$ week & $4^{\text {th }}$ week & $5^{\text {th }}$ week \\
\hline acillus firmus & 686.0 & 1140.0 & 907.0 & 890.0 & 890.0 \\
\hline Bacillus lentus & 876.0 & 804.0 & 914.0 & 855.0 & 800.0 \\
\hline Pseudomonas aeruginosa & 872.0 & 2200.0 & 2500.0 & 1900.0 & 1800.0 \\
\hline Bacillus alvei & 507.0 & 600.0 & 750.0 & 700.0 & 800.0 \\
\hline$C$ & 400.0 & 520.0 & 550.0 & 500.0 & 480.0 \\
\hline
\end{tabular}

Tab. 5 Results of identification tests on the BUMs*

\begin{tabular}{|c|c|c|c|c|c|c|c|c|c|c|c|c|c|c|c|}
\hline$\sum_{\infty}$ & 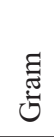 & 邑 & 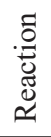 & 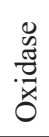 & 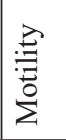 & $\begin{array}{l}\frac{0}{\circ} \\
\frac{0}{\Xi}\end{array}$ & 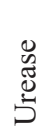 & $\begin{array}{l}0 \\
0 \\
0 \\
0 \\
0\end{array}$ & 离 & $\begin{array}{l}0 \\
0 \\
0 \\
\text { 犃 } \\
\Sigma\end{array}$ & 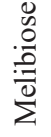 & 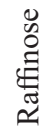 & $\frac{0}{\infty}$ & 莺 & 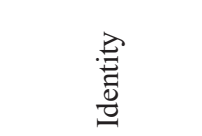 \\
\hline 1 & & GPR & & - & + & + & - & + & - & - & - & - & - & - & Bacillus firmus \\
\hline 2 & & GPR & & + & + & + & - & + & - & - & - & - & - & - & Bacillus lentus \\
\hline 3 & & GNR & & + & + & + & - & + & - & + & - & - & - & - & P. aeruginosa \\
\hline 4 & & GPR & & + & + & - & + & + & - & - & + & + & + & - & Bacillus alvei \\
\hline
\end{tabular}

* Note: A positive sign (+) indicates that the BUM tested positive during the test, while a negative (-) sign means that the BUM tested negative during the identification test.

GNR means the Gram Negative Reaction, whereas GPR means the Gram Positive Reaction. 


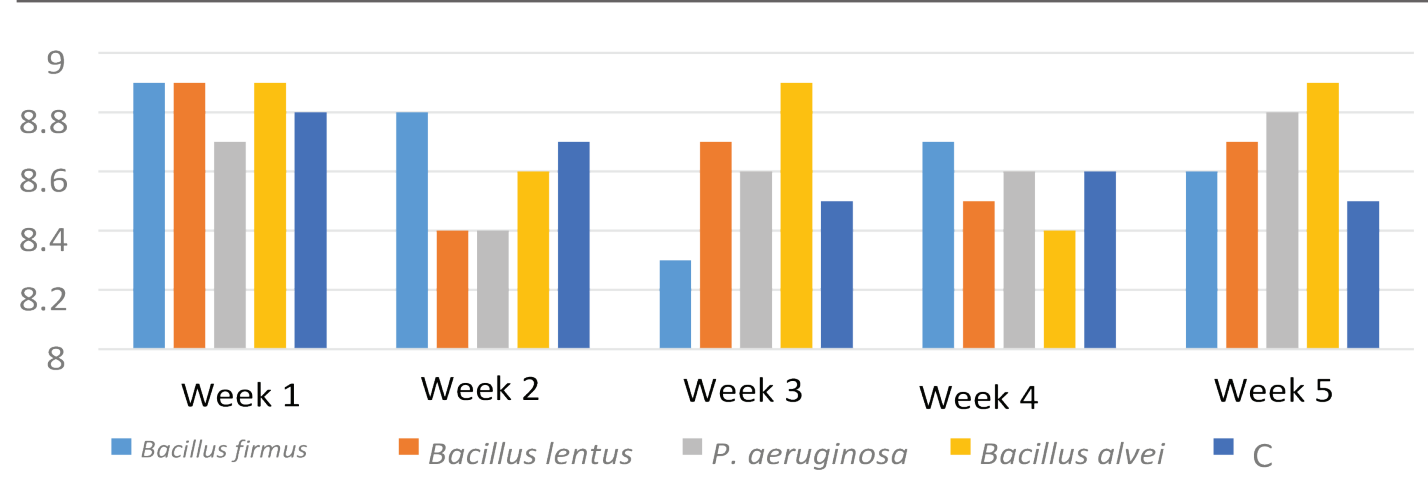

Fig. 5 pH values in flasks 1 to 4 and $C$

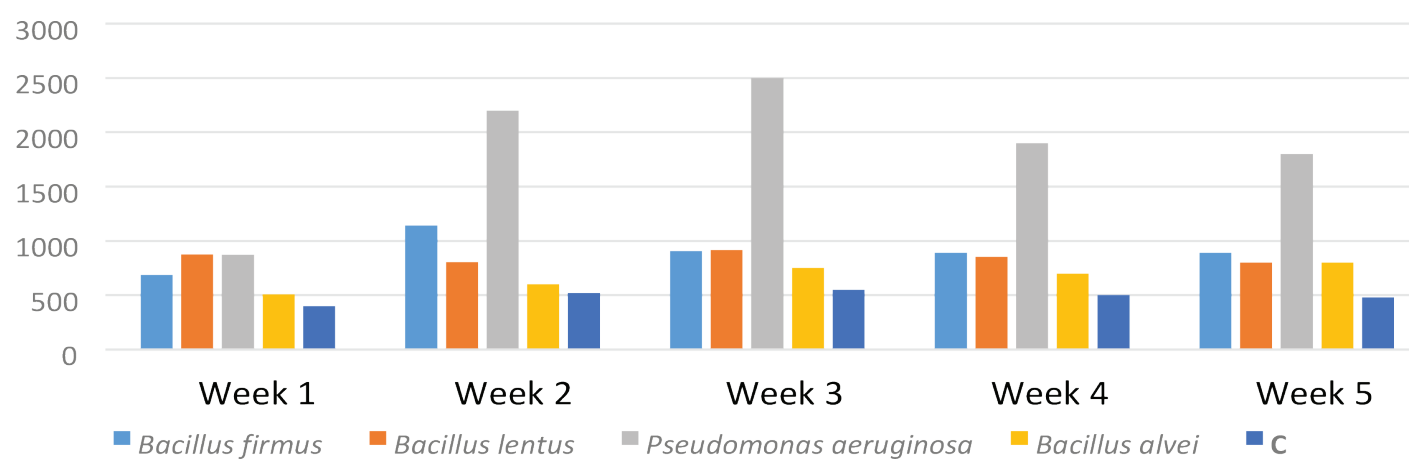

Fig. 6 Turbidity (NTU) values in flasks 1 to 4 and C

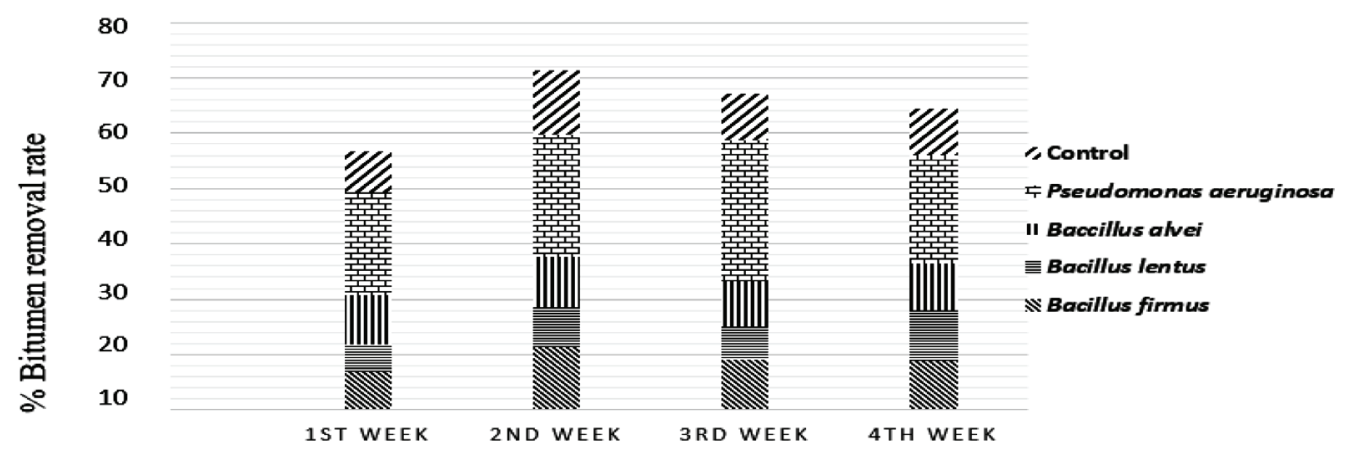

Fig.7 Percentage of bitumen removal of the BUM and Control $C$

in improving the quality of the water by removing the pollutants concerned in the influent. A further addition would be to provide a treatment facility that is effective and affordable for use by the people living in the bitumen-rich area to reduce health risks in the form of a multi-stage Bitumen-Polluted Water treatment system.

\section{CONCLUSION}

The BUM with the highest bitumen removal was the Pseudomonas aeruginosa strain, which had the highest growth rate range of $1.2 \times 10^{5}$ to $5.2 \times 10^{12}$ $\mathrm{CFU} / \mathrm{mL}$, which suggests a high bitumen removal rate during bioremediation. The rate of removal decreased over time, partly due to the lack of nutri- ents and the building up of toxic metabolites that are harmful to the microorganisms. The highest percentage of the bitumen removal range was at 33.81 - 41.24\%, and the lowest was $21.70-24.41 \%$ for $P$. aeruginosa and Bacillus firmus. The percentage of the removal rate was highest at 41.24 to $33.81 \%$ and the lowest at 24.41 to $21.70 \%$. The results indicate that the method is useful in improving the quality of bitumen-affected water bodies on a small-to-medium scale approach. 


\section{REFERENCES}

Adebusoye S. A. - Ilori M. O. - Amund O. O. - Teniola O. D. - Olaope S. O. (2007) Microbial degradation of petroleum hydrocarbons in polluted tropical stream, World Journal of Microbiology and Biotechnology, 23, 1149-1159.

Adegoke O. S. (2000) Historical perspective of bitumen/tar sand development in Southwestern Nigeria, Proceedings. of the $1^{\text {st }}$ International Summit on Bitumen in Nigeria, 131-140.

Alexander M. (1999) Biodegradation and Bioremediation, Academic Press, San Diego, CA, U.S.A., 1-70.

Amund O. O. - Igiri C. O. (2000). Biodegradation of petroleum hydrocarbon under tropical estuarine conditions. World Journal of Microbiology and Biotechnology 6:255-262.

APHA (American Public Health Association) (2005) Standard Method for the Examination of Water and Wastewater, 21st edition, Washington D.C, 1- 400.

ASCE (American Society of Civil Engineers) (2004) Natural Attenuation of Hazardous Wastes, ASCE, Reston, VA, U.S.A. 256:70.

Atlas R. M. - Bartha A. (1992) Hydrocarbon biodegradation and an oil spill bioremediation. Adv. Microbial. Ecol.,12:287 - 338.

Atlas R. M. (1981) Microbial degradation of petroleum hydrocarbons: an environmental perspective, Microbiol. Rev. (45) 180-209.

Atojunere E. E. - Ogedengbe K. - Afolayan S. O. (2010) Effects of Bitumen Deposits and Seepage on Soil-Water Physico-Chemical and Hydrological Properties in Agbabu, Southwestern Nigeria, Global Journal of Engineering and Technology, Institute of Science and Techn., Calcutta, India, 3(2):257-261.

Atojunere E. E. - Ogedengbe K. - Lucas E. B. (2018) The Development of Filtration and Bioremediation Technique for Decontaminating Bitumen-Polluted Water. International Journal of Environmental Pollution and Remediation (IJPER) Avestia Publishing, Ontario, Canada, 7(4), 19-28.

Atojunere E. E. - Ogedengbe K. (2019) Evaluating Water Quality Indicators of Some Water Sources in the Bitumen-Rich Areas of Ondo State, Nigeria, International Journal of Env. Pollution and Remediation (IJPER) Avestia Publishing, Ontario, Canada, 7(1) 9-22.
Chaineau C. H. - Rougeux C. - Yepremian S. - Oudot J. (2005) Effect of nutrient concentration on biodegradation of crude oil and associated microbial population in the soil, Soil Biology and Biochemistry, Elsevier, 37: 1490-1499.

Holt J. G. - Krieg N. R. - Sneath P. H. A. - William S. T. (1994) Bergey's manual of definitive Bacteriology, 9th edition, William and Wilkins, Baltimore, Md, U.S.A.

Leahy G. J. - Colwell R. R. (1990) Microbial degradation of hydrocarbons in the environment, Microbiological Reviews, 305-315.

Nwachukwu S. C. U. (2001) Bioremediation of sterile agricultural soils polluted with crude petroleum by application of the soil bacterium, Pseudomonas putida, with inorganic nutrient supplementation, Current Microbiology, 42 (2):231-236.

Obayori O. (2008) Degradation of some petroleum hydrocarbon pollutants by microorganisms from contaminated soil by P. aerugi$n o s a$, International Journal of Nature and Science U.S.A.

Oboh B. O - Ilori M. O. - Akinyemi J. O. - Adebusoye S. A. (2006) Hydrocarbon degrading potentials of bacteria isolated from a $\mathrm{Ni}$ gerian bitumen (tar sand) deposit, Nature and Science, 4, 51-57.

Okoh A. I. (2006) Biodegradation alternative in the cleanup of petroleum hydrocarbon pollutants, Biotechnology and Molecular Biology Review, 1, 38-50.

Olabemiwo O. M. - Adediran G. O. - Adekola F. A. - Adelowo O. O. - Olajire A. A. (2011) Preliminary Study on Biodegradation of Nigerian Natural Bitumen, Microbiology Journal, doi: 201110.3923/mj.2011.

Oyetibo G. O. - Ilori M. O. - Adebusoye S. A. - Obayori O. S. - Amund O. O. (2010) Bacteria with dual resistance to elevated concentrations of heavy metals and antibiotics in Nigeria contaminated systems. Environmental Monitoring Assessment, 168:305-314.

Rittmann B. E. - McCarty P. L. (2001) Environmental Biotechnology: Principles and Applications. McGraw-Hill, NY, U.S.A. 1-80.

Umanu G. - Nwachukwu S. C. U. - Oso S. O. (2013) Enhanced degradation of hydrocarbon in spent engine oil contaminated soil by Pseudomonas aeruginosa. International Journal of Science and Nature, U.S.A. 4(4): 611-618. 